\title{
De "turistas" y"peregrinos": identificaciones, territorialidades y fronteras en la construcción del cuerpo devoto del culto a la Virgen del Cerro en la ciudad de Salta, Argentina*
}

Daniela Nava Le Favi**

Recibido:30 de enero de 2017 - Aprobado: 19 de abril de 2017

\section{Pesumen}

Este trabajo intenta abordar las representaciones sociales que se construyen desde la prensa local alrededor de las personas que participan del culto a la Virgen del Corazón Eucarístico de Jesús, más conocida como la Virgen del Cerro, en la ciudad de Salta (Argentina). Desde una mirada sociosemiótica, interesa pensar la manera en la que se produce un corrimiento representacional en la categorización de los cuerpos que pasan de nominarse primero como "turistas" para luego, también, ser "peregrinos". Este proceso encuentra algunas respuestas en la configuración cultural, histórica, política y religiosa en el que se emplaza el culto y que inscriben los significados de los discursos analizados. Al mismo tiempo, la forma en la que se nominan los cuerpos devotos habla de fronteras (simbólicas y materiales) que implican una tensión territorial e identitaria por el monopolio religioso y, en otros momentos, por aspectos económicos. Las disputas de significación pasan necesariamente por cómo se van construyendo los cuerpos dentro del culto y cómo se configuran determinados sistemas representacionales en una advocación que posee una visibilidad y legitimidad nacional (e internacional) más que local.

La indagación se constituye en una primera aproximación que busca contribuir a los estudios sobre religiosidad y, en especial, a los que ponen foco en apariciones marianas en diálogo con aportes que provienen de la comunicación/cultura.

Palabras clave: apariciones marianas; turismo; identificaciones; territorialidadesfronteras

Artículo de reflexión. El trabajo se enmarca dentro de un proyecto de beca doctoral del CONICET "Representaciones sociales, identidad(es) y territorialidad(es) local(es). El caso de la Virgen del Milagro, la Virgen del Cerro y la Virgen de Urkupiña en Salta (Siglo XXI)". DOI: http://dx.doi.org/10.15332/s0120-8454.2017.0091.09

\footnotetext{
Becaria doctoral del CONICET, cuya labor desarrolla en el Instituto de Investigaciones en Ciencias Sociales y Humanidades (ICSOH-CONICET). Doctoranda en Comunicación Social de la Facultad de Periodismo y Comunicación Social de la Universidad Nacional de la Plata. Licenciada en Ciencias de la Comunicación por la Universidad Nacional de Salta (UNSa). Desempeña tareas docentes en las cátedras de Semiótica General, Análisis del Discurso y Semiótica de la Cultura en la carrera de Licenciatura en Ciencias de la Comunicación de la Facultad de Humanidades (UNSa). Correo electrónico:danielanavalefavi@gmail.com. CP4400. ORCID: orcid.org/0000-0002-2739-8798
} 


\section{Of "tourists" and "pilgrims": identifications, territorialities and borders in the construction of the devout body of the cult of the Virgen del Cerro in the city of Salta, Argentina*}

Daniela Nava Le Favi**

\section{Abstract}

The work tries to approach the social representations that are constructed from the local press around the people who participate in the cult to the 'Virgen del Corazón Eucarístico de Jesús', better known as the 'Virgen del Cerro' in the city of Salta- Argentina. From a socio-semiotic perspective, it is interesting to think of the way in which a representational shift occurs in the categorization of the bodies that go from being nominated first as "tourists" and then, also, to be "pilgrims". This process finds some answers in the cultural, historical, political and religious configuration in which the cult is placed. These meanings inscribe the discourse analyzed. At the same time, the way in which the devout bodies are nominated speaks of boundaries (symbolic and material) that imply a territorial and identity tension by the religious monopoly and, at other times, by economic aspects. The disputes of signification necessarily go through how the bodies are built within the cult and how certain representational systems are configured in an advocacy that has visibility and legitimacy national (and international) rather than local.

The inquiry is constituted in a first approximation that seeks to contribute to studies on religiosity and, especially, those that focus on Marian apparitions in dialogue with contributions that come from communication / culture.

Keywords: Marian apparitions; tourism; territorialities; identifications; borders

Reflection article. The work is framed within a project of a CONICET doctoral scholarship "Social representations, identity(ies) and local territoriality(ies). The case of the Virgin of the Miracle, the Virgin of the Hill and the Virgin of Urkupiña in Salta (Twenty-first century)". DOI: http://dx.doi.org/10.15332/s0120-8454.2017.0091.09

* CONICET Doctoral scholarship, whose work is developed in the Institute of Research in Social Sciences and Humanities (ICSOH-CONICET). Doctorate in Social Communication from the Faculty of Journalism and Social Communication of the National University of La Plata. Graduate in Communication Sciences from the National University of Salta (UNSa). She teaches in General Semiotics, Discourse Analysis and Semiotics of Culture in the Bachelor's Degree in Communication Sciences of the Faculty of Humanities (UNSa). Email: danielanavalefavi@gmail.com. CP4400. ORCID: orcid.org/0000-0002-2739-8798 


\title{
« Touristes » et « pèlerins »: identifications, territorialités et frontières dans la construction du corps dévoué du culte de la Vierge del Cerro dans la ville de Salta, en Argentine*
}

\author{
Daniela Nava Le Favi**
}

\section{Résumé}

Cet article tente d'aborder les représentations sociales qui se construisent à partir des médias locaux au sujet des personnes qui participent au culte de la Vierge du Cour Eucharistique de Jésus, mieux connue sous le nom de la Vierge del Cerro, dans la ville de Salta (Argentine). D’un point de vu socio-sémiotqiue, il est intéressant de penser la manière dont ce produit un changement de représentation dans la catégorisation des corps qui passent de s'appeler tout d'abord «touristes », pour ensuite être aussi des «pèlerins». Ce processus trouve des réponses dans le contexte culturel, historique, politique et religieux dans lequel se développe le culte et qui inscrivent les significations des discours analysés. En même temps, la façon dont on dénomine les corps dévoués réflète des frontières (symboliques et matérielles) qui impliquent une tension territoriale et identitaire pour le monopole religieux et, à d'autres moments, pour des aspects économiques. Les conflits de signification passent nécessairement par la façon dont les corps se construisent dans le culte et la façon dont se configurent certains systèmes de représentation dans un dévouement qui a une visibilité et une légitimité nationale (et internationale) plus que locale.

L'enquête constitue une première approche qui vise à contribuer aux études sur la piété, et surtout à celles qui mettent l'accent sur les apparitions mariales en dialogue avec les contributions provenant de la communication / culture.

Mots clés: apparitions mariales; tourisme; identifications; territorialités-frontières

\footnotetext{
Article de réflexion. Ce travait fait partie d'un projet pour une bourse de doctorat du CONICET "Représentations sociales, identité(s) et territorialité(s) local(es). Le cas del Vierge du Miracle, la Vierge del Cerro et la Vierge de Urkupiña à Salta (Siglo XXI)". DOI: http://dx.doi.org/10.15332/s0120-8454.2017.0091.09

Étudiante du Doctorat en Communication de la Faculté de Journalisme et Communication de l'Université Nationale de la Plata. Boursière du doctorat du CONICET, dont le travail se déroule à I'Institut de Recherches en Sciencies Sociales et Humaines, ICOSH-Unité Exécutive du CONICET. Licence en Sciences de la Communication de I'Université Nationale de Salta et professeur en Sémiotique Générale et Sémiotique de la Culture de la même licence. Email: danielanavalefavi@ gmail.com. CP4400. ORCID: orcid.org/0000-0002-2739-8798
} 
¿Existe un buen modo de categorizar los cuerpos?

¿Qué nos dicen las categorías?

Las categorías nos dicen más sobre la necesidad de categorizar los cuerpos que sobre los cuerpos mismos.

Judith Butler, 2011

\section{Introducción}

Cada sábado, la ciudad de Salta, Argentina, ${ }^{1}$ es testigo de cómo diversas empresas turísticas emprenden el viaje a una de las cimas de los cerros más altos que rodean la capital. Allí, una mujer, María Livia Galliano de Obeid, asevera "ver" y "oír" a la Virgen. Miles de fieles asisten para participar del ritual de imposición de manos, momento en el cual la mujer roza el hombro de la persona, produciendo que algunos se desmayen o afirmen ser sanados de alguna dolencia o enfermedad.

La Virgen del Corazón Eucarístico de Jesús, más conocida como la Virgen del Cerro, es una de las apariciones marianas en Argentina que se ha prolongado en el tiempo, pero, a diferencia de otras como la Virgen del Rosario de San Nicolás, no cuenta con el apoyo del arzobispado de la Iglesia Católica local (Ameigeiras, 2012; Suárez y Marchetta, 2015; Fogelman Ceva y Touris, 2013). La vidente se ha resistido a asumir las directivas pastorales, generando ciertas tensiones que se pueden divisar en los dos comunicados emitidos por la institución: uno, en el año 2003, denominado "La cuestión pastoral de la Ermita del Cerro" y el otro, en el 2006, titulado "La cuestión del Cerro". A pesar de ello, la organización del culto promueve fuertes estrategias para la instalación y consolidación de la advocación basadas en la estructura mítica del relato de la aparición (inscripto en la tradición católica) y los modos en que el fenómeno se expande o establece territorialmente en cuatro instancias: los sábados en la cima del cerro; el encuentro mensual donde María Livia responde las preguntas de los fieles; los grupos de oración, y las peregrinaciones a Salta desde diversos lugares del mundo (Ameigeiras, 2012).

A nivel país, la organización mariana suma adeptos de otras diócesis y, en general, los fieles son "turistas" nacionales y extranjeros. La menor participación de los habitantes de la ciudad (y la provincia) está vinculada a la manera en la que se vive la religiosidad aferrada, en gran medida, a los parámetros del catolicismo tradicional popular (Suárez y Marchetta, 2015) y a la existencia de un

1 Salta es una ciudad, un municipio y la capital de la provincia de Salta, República Argentina, que tiene una población de 535.303 habitantes, siendo la ciudad más poblada de la provincia y la séptima del país. Información obtenida de: http://estadisticas.salta.gov.ar/web/ 
proceso religioso colonial de gran legitimidad en el seno local, como el culto del Milagro, sedimentado desde diferentes esferas (la eclesial, la mediática e, incluso, la devocional) como el ícono de la identidad local (Nava Le Favi, 2013, 2015).

Los medios de la prensa nacional visibilizan positivamente la manifestación del Cerro, dejando de lado las tensiones existentes con la Iglesia en Salta (Ameigeiras, 2012). Sin embargo, a nivel local, la prensa ha asumido otra postura: se observa en los fragmentos analizados un corrimiento representacional que pasa de categorizar a las personas ${ }^{2}$ que participan del culto como "turistas" a nominarlas, también, como "peregrinos". Así, por ejemplo, las identificaciones inscriben al cuerpo en una dimensión económica que sitúa al peregrino en la relación oferta-demanda: "turistas dejaron su comentario en la Secretaría de Tránsito del municipio" (El Tribuno de Salta, 27 de julio de 2012). Ese cuerpo categorizado, también, está inscripto en un fenómeno religioso que le vale su identificación como "peregrino", pero que tiene una diferencia territorial que no lo ubica dentro del espacio local "se espera a miles de peregrinos de todas las provincias" (El Tribuno de Salta, 10 de diciembre de 2016). Este proceso tiene ciertas correlaciones con la configuración cultural, política, económica y religiosa en la que se enmarca la advocación del Cerro, las cuales el trabajo trata de mapear para comprender los sentidos que impregnan las representaciones de la prensa. La reflexión supone que ese corrimiento implica una puja por la legitimidad del culto como práctica religiosa y "salteña".

La indagación retoma, principalmente, la línea de los estudios latinoamericanos que piensan la relación entre comunicación-cultura (Martín Barbero, 2003; Ford, 1985; Reguillo, 2008; Grimson, 2012), la teoría de las representaciones sociales (Cebrelli y Arancibia, 2005,2010; Rodríguez, 2008, 2011,2014), de las identidades (Brubaker y Cooper, 2002; Hall y Du Gay,2003), enfoques sobre el territorio (Foucault, 2004; Segato, 2008; Arancibia, 2009) y los aportes provenientes de los estudios relacionados a la religiosidad mariana (Chaile, 2010; Fogelman, 2005; Ameigeiras y Suárez, 2009, 2010, 2011, 2013; Ameigeiras, 2012; Suárez y Marchetta, 2015; Nava Le Favi,2013, 2015, 2016).

El corpus comprende enunciados significativos seleccionados durante el periodo 2012-2016 pertenecientes a tres medios de la prensa local: el diario El Tribuno de Salta, La Gaceta de Salta y Punto Uno de Salta, elegidos por ser los que mayor cobertura han dado a la advocación. El primer diario mencionado es uno de los fundadores de la prensa en la provincia y los demás poseen una fuerte impronta oficialista, con lo cual podría leerse allí la posición del actual gobierno provincial. $^{3}$ Además, los tres tienen una mirada conservadora y tradicionalista, una constante que se repite en la prensa de tirada local. El análisis de la información

2 El trabajo utiliza de manera indistinta las categorías de fieles, peregrinos, promesantes y devotos para designar al grupo de personas que participan del culto. Las diferenciaciones son rigurosas y se mantienen los lexemas de los enunciados al momento del análisis de las textualidades, es decir, aquellas que Bourdieu (2013) denominaría "las categorías de la práctica".

3 Desde el año 2007 se encuentra en la gobernación de Salta el Dr. Juan Manuel Urtubey, el cual se autoidentifica como "peronista" Fuente: http://www.perfil.com/politica/urtubey-definitivamente-el-kirchnerismo-se-acabo-dentro-delperonismo-0208-0010.phtml 
se realizará desde una perspectiva sociosemiótica de los discursos (Angenot, 1998; Verón, 2007; Charaudeau, 2003) que, junto a una miradaantropológica (Maluf, Magalhaes, y Caggiano, 2008), ayude a comprender el contexto económico, histórico y político de las textualidades. Esta mirada posibilita leer cómo los discursos masivos tejen fronteras simbólicas y/o proponen clausuras de significación (Rodríguez, 2014) sobre los cuerpos que se categorizan, promoviendo, además, una reflexión sobre los medios y su centralidad en construir o reproducir identificadores sociales que ponen en circulación representaciones sobre la mismidad, la diferencia y la alteridad (2014).

La indagación piensa las representaciones como mecanismos traductores que tienen "una facilidad para archivar y hacer circular con fluidez conceptos complejos cuya acentuación remite a un sistema de valores y a ciertos modelos de mundo de naturaleza ideológica" (Cebrelli y Arancibia, 2005, p. 38). La representación suele tener una alta recurrencia en la formación discursiva en el momento de producción, lo que le otorga ciertos rasgos hipercodificados que posibilitan su reconocimiento inmediato (2005). Además, como articulación, permite estudiar la relación del sujeto, las adscripciones identitarias y las formaciones discursivas como correspondencias no necesarias, como contingencias que reactivan los procesos históricos (Laclau y Mouffe, 2005) y que se entraman o leen en los intercambios comunicativos que dan cuenta de las complejas trayectorias que construyen las identidades nunca suturadas de manera definitiva (Cebrelli y Arancibia, 2010). Como lo plantea Stuart Hall (1984), la identificación es condicional, pues sus condiciones de existencia están determinadas por los recursos materiales y simbólicos en los que se sostiene. El proceso constitutivo de las identidades es un trabajo de diferencia desde lo discursivo y desde los sistemas representacionales en lucha y/o conflicto, legibles según los regímenes de visibilidad imperantes en un estado de sociedad (Hall y Du Gay, 2003). En este sentido, el trabajo supone que las identificaciones pueden ser situacionales, porque en diferentes momentos un actor o fenómeno ocupa un rol determinado; son construidas porque devienen de su diálogo con lo social; son relacionales porque en la medida que se construye un "yo-nosotros" hay "otros" que entran en la relación de identificación; son estratégicas porque existe autoidentificación o se identifica a otros de tal o cual modo conociendo las resonancias e implicaciones de las categorías que usan ${ }^{4}$ (Brubaker y Cooper, 2002). Este marco conceptual posibilita observar cómo un mismo cuerpo se inscribe en diferentes identificaciones: así, los fieles son "peregrinos" para la organización del culto y, por momentos, para los medios locales son "turistas". La indagación piensa que esos cuerpos discursivos son el resultado de un acontecimiento construido que instaura un sentido particular y específico, su materialidad es "comprendida" y "sentida" relacionalmente desde el discurso que la sustente y, en este caso, atravesados por un proceso de mediatización (Varela, 2010). En los enunciados, los cuerpos van permeando e inscribiéndose en territorialidades e

4 Brobaker y Cooper (2002) hablan de una quinta forma de identificación: las racionales. Las mismas suponen que ciertos usos estratégicos subrayan una dimensión de la acción social: su racionalidad. El trabajo utilizará la noción de identificaciones estratégicas para designar, también, a aquellas que son racionales, dado que ambas, de algún modo, implican una dimensión de racionalidad en el proceso de identificación. 
identificaciones que permiten leer, también, el campo representacional en el que se vive y piensa el culto en Salta: "vienen a la ciudad para orar ante la Virgen del Cerro, considerada milagrosa" (El Tribuno de Salta, 27 de julio de 2012). La frase, como otras que se analizan a lo largo del trabajo, permite dar cuenta de la legitimidad del culto, es decir, cuerpos que participan de un fenómeno que se "considera" milagroso -aunque se omita quienes afirman tal atribución-, en tanto se marca aquellos que no pertenecen al espacio local de la "ciudad", sino que son los que "vienen" de un afuera, enunciado que alberga una mirada por cómo se piensan las territorialidades inscriptas en los cuerpos.

Los territorios (materiales y simbólicos) albergan identificaciones y se constituyen en una representación que instala preguntas como "quién soy", "dónde estoy", "a qué nosotros pertenezco", "dónde me localizo" y "qué lugar ocupo, cómo me relaciono con él y qué historias me entraman a él" (Arancibia, 2009). La territorialidad es una experiencia particular, histórica y culturalmente definida de ese territorio (Foucault, 2004), donde diversos actores entraman en él sus relatos, construyen los múltiples rostros de las identidades individuales y colectivas (Segato, 2007; Arancibia, 2009). Las territorialidades también van demarcando fronteras identitarias, concepto retomado desde la perspectiva de Grimson (2012), donde la nacionalidad es un modo de interpelación. En este punto, el trabajo insiste en observar las maneras sedimentadas de ver a un "otro" diferente a un "nosotros", sin desconocer que también hay construcciones disímiles de significaciones entre un lado y otro de la frontera, aunque los medios se encargan de cristalizar miradas dicotómicas de esas heterogeneidades (Cebrelli y Arancibia, 2005; Rodríguez, 2014). De esta manera, en el corpus se puede observar que aquel que asiste al culto no solo es un "no-salteño", sino que, al ubicarlo como "turista", se tiñe el cuerpo de una territorialidad "externa", demarcando fronteras entre uno y otro cuerpo, produciendo el efecto de generar miradas dicotómicas que obturan la diversidad. El cuerpo, categoría transversal a la presente indagación, no solo está mediatizado, sino que se constituye como un efecto del poder de los discursos (Butler, 2002) que los nomina, los caracteriza y los sitúa en fronteras simbólicas ${ }^{5}$, es decir, espacios porosos que construyen, delimitan y destacan la diferencia (Cebrelli y Arancibia, 2005). En el caso analizado, las fronteras ubican a los cuerpos en determinados campos (como lo religioso y lo económico) en tensión con lo territorial e identitario. En este sentido, la categorización de los cuerpos permite reflexionar sobre cómo la prensa local, por momentos, legitima el culto dentro del ámbito turístico o turístico-religioso en detrimento de su reconocimiento como fenómeno religioso, enfocando solo su potencial económico para la provincia.

Este análisis piensa que la organización de María Livia construye una territorialidad atravesada por rituales, es decir, artefactos comunicativos que inscriben ese espacio, lo consagran y lo sacralizan (Segato, 2008). Los rituales, además, como

5 El concepto de frontera es utilizado desde una mirada sociosemiótica que permite pensar su condición material, es decir, fronteras espaciales, geográficas o jurisdiccionales. Sin embargo, el trabajo también va mapeando la dimensión simbólica de la categoría en relación a los cuerpos, es decir, como efectos del discurso que pueden o no coincidir con las fronteras materiales (Cebrelli y Arancibia, 2005). 
conductas que están relacionadas con las creencias (Turner, 1980) implican una experiencia que se traduce en una vivencia de lo sagrado atravesada por trayectorias personales y situaciones biográficas que inciden en el ritual vertebrador del culto: en la oración de intercesión, la vidente roza el hombro de los promesantes para que muchos de ellos se desmayen, lloren o afirmen ver a la Virgen, momento donde cobra relevancia la configuración de sentido que los creyentes le imprimen a la devoción (Ameigeiras, 2012). Además, esa territorialidad se impregna de elementos identificatorios que hacen pensar en la idea nación (Anderson, 1991), la cual permea el espacio y sobreimprime significados (Cebrelli y Arancibia, 2005) entre el culto y una representación de "argentinidad".

El análisis se estructura en dos partes: en la primera se intenta mostrar el contexto de surgimiento de la aparición, las pujas con la Iglesia local y las conexiones con los proyectos turísticos provinciales. En la segunda parte, se mapean algunas representaciones de la prensa local, donde las personas que participan de la advocación son pensadas como "turistas" y "peregrinos", dando cuenta de la tensiones o negociaciones de sentidos en términos identitarios, religiosos y económicos en los que se inscribe la categorización de los cuerpos.

La reflexión se constituye, en una primera aproximación, en un abordaje de las identificaciones, las territorialidades y las fronteras en procesos de religiosidad visibilizados desde los medios de comunicación. Por lo mismo, se espera contribuir a los estudios latinoamericanos en comunicación y cultura que se encuentren en diálogo con investigaciones relacionadas a fenómenos de apariciones marianas contemporáneas.

\section{Contexto de surgimiento de la advocación: entre el "turismo" y el reconocimiento de la Iglesia}

La Virgen del Cerro, como culto mariano, es un proceso que se remonta a la historia de la Iglesia Católica vinculada al crecimiento y valoración de la figura de María, la cual se inicia en los primeros siglos de la cristiandad y se consolida especialmente hacia el siglo XVI y la Edad Media (Der Walde Moheno, 1997). Se trata de una devoción que se trasladó posteriormente a América, en la cual se enraizó por la evangelización facilitada por tradiciones religiosas presentes en los pueblos originarios, donde ha sido fuerte la presencia de la Madre Tierra y otras deidades femeninas (Ameigeiras, 2012; Fogelman, 2005; Chaile, 2010). Desde fines del siglo pasado, en el catolicismo se desplegó un reconocimiento fundamental a la imagen mariana, dado que permitía desplegar una modalidad litúrgica superadora de la rigidez doctrinaria, cuya consecuencia fue la creciente expansión de la devoción y su instalación en el imaginario de los creyentes (Ameigeiras, 2012; Fogelman, 2005).

Durante el último cuarto del siglo XX, América Latina contó con numerosas apariciones y, en Argentina, la Virgen del Cerro es la segunda, después de la 
Virgen de Rosario de San Nicolás. Sin embargo, las formas de legitimación entre ambos cultos son diferenciales debido a que, en el último caso, la vidente Gladys Motta se desplazó del centro del acontecimiento dejando que la Iglesia de la localidad asumiera plenamente el manejo y reflexión del culto (Ameigeiras, 2012).

En Salta, María Livia, mujer casada y madre de tres hijos, no ha dejado su protagonismo en el suceso y ha provocado fuertes tensiones con la Iglesia en Salta ${ }^{6}$, institución que tiene un rol de importancia en la historia local, la cual puede comprenderse a través del culto del Milagro: una devoción que fue instrumento de vehiculización de las imágenes de mundo católicas (Nava Le Favi, 2013). Desde la etapa colonial, la festividad le permitió a la institución constituirse como un elemento integrador entre mestizos e indios (Chaile, 2010). Este proceso se fue forjando en medio de una sociedad con fuertes tradiciones hispanoindígenas, con una estructura social segmentada en la oligarquía criolla que se vanagloriaba de su origen patricio y de su linaje aristocrático y español (Álvarez Leguizamón, 2010). La Iglesia, a través del culto, pudo erigirse en la etapa de constitución de los estados nacionales como un valor del salteño, lo que le posibilitó a la provincia encontrar rasgos distintivos frente a las otras jurisdicciones (Álvarez Leguizamón, 2010), una representación aún sedimentada en la actualidad (Nava Le Favi, 2013).

En una ciudad tradicionalista con fuerte presencia de la Iglesia Católica, María Livia afirma desde el año 1990 comenzar a recibir mensajes de la Virgen, suceso coincidente con un momento histórico, político y económico neoliberalista para el país, que se caracterizó por "el desmantelamiento del Estado interventor y la destrucción del modelo de industrialización por sustitución de importaciones" (Campos, 2009, p. 95). Durante este periodo se ha registrado una serie de emergencias religiosas donde se mezclan los símbolos, los fetiches, los rituales, las creencias oficiales y no oficiales ayudando a reconstruir la identidad, y en muchos casos la solidaridad, como base del tejido social (Dri, 2003). En este sentido, el culto tiene la particularidad de que, si bien hay elementos tradicionalistas y conservadores del dogma católico (principalmente en los discursos que rodean al mismo), la práctica del ritual pasa necesariamente por el cuerpo peregrino (que se desmaya, que se sana ante el contacto con María Livia) donde la configuración del sentido del ritual cobra mayor importancia que la estructura del mismo (Ameigeiras, 2012). Sumado a ello, la mediadora entre la persona y la divinidad es una mujer, rompiendo los esquemas de la institución que siempre ha reservado un lugar excluyente al género. Esto permitiría ver cómo el culto conjuga (entre los rituales, los actores y los discursos) creencias del catolicismo y otras no legitimadas por el mismo.

Los mensajes -que emite la divinidad y solo escucha la vidente-cumplen un rol de verdadera importancia en el culto: a partir de ellos, la Virgen le "indica" a María Livia lo que debe hacer. Así, por ejemplo, en el año 1995 el pedido radica en

6 A pesar de la falta de aval del arzobispado local, la organización de María Livia se ha esforzado en abrir redes de vinculación con instituciones católicas regionales, nacionales e incluso internacionales, este último aspecto verificable en las visitas de René Laurentín al cerro, experto reconocido en el tema y vinculado al vaticano (Ameigeiras, 2012). 
que se dirija al Monasterio San Bernardo de Carmelitas Descalzas de Salta ${ }^{7}$, uno de los pocos segmentos de la Iglesia local que brinda apoyo a la organización. En el año en que la Virgen "emite" el mensaje, asume la gobernación de Salta el Dr. Juan Carlos Romero, quien estaría en el poder hasta el 2007. Durante su gobierno, realiza un "fuerte ajuste a la economía provincial, 'sanea' las cuentas públicas a costa de la privatización de la mayoría de los servicios públicos con los consecuentes despidos masivos y la baja compulsiva de los salarios" (Álvarez Leguizamón y Villagrán, 2010, p. 218). Su política basada en el turismo ${ }^{8}$ y mercantilización de la cultura implicó resaltar arquitectónicamente una imagen del pasado glorioso, exaltando el origen hispano de la identidad salteña (2010). El gobierno de Romero reactiva los discursos casi fundacionales de la provincia, situación similar a la que ocurría a fines del siglo XIX y principios del XX, cuando se resaltaba la "tradición" sin dejar de lado el proyecto modernizador en el que se anclaba la incipiente nación para caracterizar a Salta (Flores Klarnick, 2010). De esta manera, el discurso fundacional se reactiva con ciertas adaptaciones en la época romerista: la cultura -basada en territorialidades y valores colonialistas- eran para el exgobernador un recurso clave para inscribir a Salta en los tiempos globalizados (Álvarez Leguizamón y Villagrán, 2010).

En el año 2001 se instala el culto en una de las cimas que rodea la ciudad a "pedido" de la Virgen y en contracorriente a las autorizaciones de la Iglesia local. A partir de allí, todos los sábados llegan miles de "peregrinos" (categoría utilizada por la organización del culto) para participar de la oración de intercesión y la imposición de manos de la vidente. En este sentido, podría pensarse que existen ciertas coincidencias entre el momento de surgimiento y visibilización del culto con la política planteada por Romero: la advocación del Cerro mantiene conexiones con la cultura colonialista que se intenta rescatar durante este periodo económico y político de la provincia. La Virgen es, en sí, una representación católica, es decir, una imagen de una institución que atravesó la colonia y la constitución de los estados nacionales y tuvo un rol activo en la delimitación de la identidad del "salteño" a fines del siglo XIX y principios del XX. Así, no solo se observa la cultura tradicionalista del culto en la utilización de la imagen de una Virgen, sino, también, en el mismo discurso que enuncia María Livia donde se presenta "una reafirmación de una ortodoxia cristiana católica en el marco de planteos teológicos y pastorales tradicionalistas y conservadores" (Ameigeiras, 2012, p. 222). Además, se debe tener en cuenta la imagen en la que ella (y la organización) se enmarca9: es madre, esposa, ama de casa, representaciones

7 El Convento San Bernardo de la Ciudad de Salta es un templo católico construido a fines del siglo XVI o comienzos del siglo XVII. En el año 1846, el presbítero Don Isidoro Fernández hizo venir de Chile unas monjas Carmelitas Descalzas con el fin de crear un beaterio al que dio el Nombre "Nuevo Carmelo de San Bernardo". Así, lo que en un principio era un hospital, quedó convertido en el convento que permanece hasta nuestros días. Información extraída de: http://www. portaldesalta.gov.arl

8 En las proyecciones generales que planteaba Romero para la provincia, se encontraba el subsector turismo como una de las problemáticas que pretendía abordar su gobierno. De esta manera, consideraba cuatro puntos a tratar: la comercialización, "vinculada a la acción de promoción" ; los atractivos, que clasificaba en "naturales, históricos y culturales" ; la infraestructura, y los servicios, que debían mejorarse. Información extraída de: Salta, bases para un plan de obras y programa de Gobierno. Documento preliminar 1996-2000 de Juan Carlos Romero.

9 La forma de nominar a María Livia como madre, esposa y ama de casa se encuentra en la historia del culto que brinda la organización a los fieles y está disponible en la página oficial del culto: http://www.inmaculadamadre-salta.org/obra/ 
de mujer que legitiman una mirada conservadora y patriarcal sobre la vidente (Nava Le Favi, 2014). De esta manera, el culto a la Virgen del Cerro podría constituirse como un fenómeno que se adapta perfectamente a los objetivos delineados por el exgobernador: es una conjunción entre un pasado colonial y un proyecto político de provincia que fomenta el turismo (Nava Le Favi, 2013).

Además de las estrategias para la instalación y consolidación devocional ya mencionadas, el culto presenta ciertas identificaciones con una idea de "nación" basada en la recuperación de los colores que configuran los emblemas argentinos en, al menos, dos instancias: una relacionada con la imagen de la Virgen y la otra, con algunos elementos dispuestos en la cima del cerro. Respecto a la imagen de la divinidad, cabe pensar las coincidencias existentes con la Virgen del Inmaculado Corazón de María. Más allá de los colores característicos marianos (el blanco y celeste), hay ciertas recurrencias en elementos como el Corazón Eucarístico y las estrellas que tienen predominancia en ambas devociones. Se podría sostener que existe una hipercodificación, es decir, un proceso embrionario que parte de un código ya existente para codificar uno que pretende ser nuevo, pero el cual se basa más en la convención que en la innovación (Eco, 2000). De esta manera, la imagen de la Virgen del Cerro encuentra similitudes con el canon católico por los signos recurrentes en relación con la Virgen del Corazón de María y por el relato mítico alrededor del culto, el cual tiene coincidencias con otras apariciones marianas en el mundo como la Virgen de Medjugorge (Ameigeiras y Suárez, 2011). Estos rasgos hipercodificados pueden comprenderse como un intento de generar aceptación de un signo ritual como la Virgen del Cerro por la Iglesia, ya que no atenta contra las bases del dogma.

La configuración de los colores de la divinidad también debe pensarse en la correlación con los que representan los emblemas argentinos. Esa recurrencia cromática también está presente en los elementos dispuestos en la cima del cerro: los carteles de señalización con pedidos de silencio o indicando los caminos para el tránsito están pintados en celeste y blanco. Además, en el escenario donde se efectúan los rituales hay banderas argentinas y papales (ninguna salteña) que van marcando e impregnando la territorialidad simbólicamente: esa exaltación de los colores remite -implícitamente- a un proceso de sobreimpresión de significados, es decir, de apropiación y reapropiación (Cebrelli y Arancibia, 2005) en el culto a la Virgen con una idea de "argentinidad".

El cerro donde se emplaza la advocación no solo se constituye en un lugar de acercamiento a lo sagrado donde se movilizan experiencias personales enmarcadas en experiencias colectivas por el ritual que realiza la vidente (Ameigeiras, 2012), sino que es un espacio significativo por cuanto se inscriben elementos identificatorios con lo nacional, lugar de procedencia de la mayoría de los peregrinos ${ }^{10}$. Por otra parte, habilita a la interpretación que el lugar donde la

10 En una encuesta realizada por Ameigeiras y Suárez en el año 2011, se arrojaba como resultado que la mayoría de los peregrinos provenía de Buenos Aires $(25,6 \%)$ y Córdoba $(15,1 \%)$ respecto al ámbito nacional, registrándose poca concurrencia de salteños, pues solo constituía el $9 \%$ del total encuestado (Ameigeiras y Suárez, 2013) 
organización de María Livia da la disputa por el reconocimiento y la legitimidad no se encuentra en el ámbito de relaciones a nivel local.

En cuanto a las representaciones de la Iglesia local respecto al culto, pueden leerse en su comunicado del año 2003, donde identificaba a los fieles mediante el uso del lexema "peregrinos", por ejemplo en la disposición número 6, en la cual se informa los horarios de oración ${ }^{11}$, mientras que en el comunicado del año 2006 los ha identificado como "personas que buscan una experiencia religiosa", además de sedimentar la imagen del culto como "una actividad de iniciativa particular en el marco de una organización civil, sin reconocimiento ni inserción en la actividad orgánica y oficial de la Iglesia Católica en Salta". ${ }^{12}$

\section{Cuerpos turistas y cuerpos peregrinos en la prensa gráfica local}

La industria actual global tiende a la competitividad "desregulada": una sociedad posmoderna caracterizada por el consumo de bienes y servicios donde el "turista" ocupa un lugar clave en la nueva estratificación social: puede elegir los espacios que transita y que consume (Bauman, 1999). En este nuevo mapa globalizado, el turismo religioso-a pesar de la tendencia a la secularización- ha emergido en diferentes regiones como uno de los productos del turismo más importante (Millán, Morales, y Pérez, 2010). Algunos de los destinos de mayor visibilidad en el mundo están vinculados a las apariciones marianas como Banneux (Bélgica), Fátima (Portugal) y Lourdes (Francia) (Ambrosio y Pereira, 2007). En el caso de este tipo de turismo en la Argentina, presenta ciertas tensiones para su desarrollo y estudio debido a la relación no armónica entre la ética católica y el espíritu del capitalismo (González Viaña, 2013).

En cuanto al culto estudiado, los medios de comunicación locales le han dado visibilidad dentro de los parámetros del turismo:

Desde hace ya algunos años, los turistas de distintas provincias no vienen a la ciudad solo atraídos por las bellezas naturales y culturales, sino por sobre todas las cosas, por la Virgen del Cerro. Este fenómeno turístico se mantiene en ascenso. El turismo religioso es el causante de una ocupación hotelera considerable del mes de marzo. (Punto Uno de Salta, 26 de marzo de 2012)

En el enunciado se puede observar que existe una confluencia entre un culto devocional que está dirigido a una clientela potencial, lo cual conlleva a una

\footnotetext{
11 El documento completo está disponible en el siguiente link: http://www.arquidiocesissalta.org.ar/cuestionpastoral/ cuestion_pastoral_2003.html

12 El documento puede visualizarse en el siguiente link: http://www.arquidiocesissalta.org.ar/cuestionpastoral/declara-
} cion2006.html 
oferta y un consumo material, como la ocupación hotelera. Allí, la persona que asiste al culto es identificada contextualmente y estratégicamente como "turista". La gente lleva el territorio a cuestas (Segato, 2008) y, en el fragmento analizado, el cuerpo discursivo se configura como una territorialidad externa a un espacio delimitado que es "la ciudad", tejiendo simbólicamente fronteras entre los que viven y no viven en Salta. Ese espacio, además, se connota positivamente a partir de la utilización de subjetivemas como "bellezas", que posibilitan enumerar el patrimonio natural. La Virgen del Cerro se identifica estratégicamente como un fenómeno turístico, es decir, una actividad económica obturando su dimensión religiosa para enmarcarla en el circuito de lo que un "adentro" de la ciudad ofrece (vende, comercializa, pone a disposición del consumo) hacia un afuera, un "turista" que se constituye como un outsider (Elías, 1996). Al categorizar el cuerpo de esa forma, se crea la idea de que las personas que participan de la advocación producen rédito económico dentro del parámetro del turismo y del turismo religioso. Sin embargo, no se los reconoce plenamente como personas creyentes ni tampoco se sitúa al culto como fenómeno religioso.

Si en el año 2012 la prensa hablaba del patrimonio cultural y del turismo (enmarcado principalmente en la Virgen del Cerro) que ofrecía la provincia, en los últimos años hay un corrimiento representacional de pasar a identificar igualitariamente la devoción del Cerro con el culto del Milagro tanto en su dimensión religiosa como económica:

Mes tras mes, la cantidad de turistas que llegan a Salta por motivos religiosos ha crecido significativamente en términos cuantitativos. El atractivo turístico de nuestra provincia ya no se limita a sus imponentes paisajes, sus mágicos pueblos o su encantador estilo colonial, sino que ahora cuenta con un factor que se ha rápidamente se ha convertido en algo característico.

"Salta cuenta con dos símbolos religiosos que son determinantes en el aumento de turistas que recibimos cada año, la fiesta del Milagro y la Virgen del Cerro", cuenta a La Gaceta Rodolfo Antonelli, Secretario de Turismo municipal, y agrega que la Catedral es uno de los lugares más visitados.

Las cifras oficiales que se dieron a conocer este año indican que de la celebración del Milagro participaron 850.000 personas, de las cuales más de 30.000 eran peregrinos del interior provincial. Si a esa cifra se le suma lo que convoca cada sábado la Virgen del Cerro, que según Antonelli son entre 15.000 y 30.000 visitantes, puede superarse tranquilamente la cifra de 1.500 .000 personas que llegan a Salta principalmente por motivos religiosos. (La Gaceta de Salta, 25 de noviembre de 2014)

En el fragmento se identifican los "turistas" que llegan a Salta para formar parte de la fiesta del Milagro y la del Cerro. Lo interesante es que en el párrafo 
se pone en pie de igualdad una devoción reconocida por el dogma con otra que ha tenido numerosas tensiones con la Iglesia local y se lo hace a través de la inserción de un testimonio perteneciente a la esfera política local. La nota también habla de "peregrinos" de una territorialidad del "interior provincial" como aquellos que vienen de un "afuera" convocado por la Virgen del Cerro. Además, hay una tendencia a la exaltación del culto del Milagro, rescatando su masividad y subsumiendo la totalidad de las personas que participan de los rituales de la vidente a la festividad reconocida por el dogma.

En los últimos años, se comenzó a acrecentar la visibilización en los medios locales de representar a los promesantes del Cerro como "peregrinos", además de que es sumamente frecuente que la prensa se refiera al culto utilizando testimonios de las personas que asisten a ver a la vidente. Podría inferirse que la legitimidad de la ritualidad queda en la voz de esos outsiders y no de actores como la Iglesia o la esfera política:

Las visitas a la cima del cerro persisten durante toda la semana, pero se profundizan cada sábado de peregrinación, como sucedió el pasado 14 de mayo, con la presencia de casi cien micros de peregrinos. Además de aquellos salteños que concurrieron.

"Hace seis años que vengo a este lugar y siempre tuve experiencias hermosas. Son milagros que se nos cumplen y uno agradece por todo lo recibido. Las manifestaciones siempre están presentes, yo experimenté varias", dijo a El Tribuno Susana Testa, de Río Negro, quien recuerda con emoción lo vivido hace algunos años. Como ella, muchos otros llegan a la pequeña capilla donde está instalada la imagen de la Inmaculada Madre. (El Tribuno de Salta, 19 de mayo de 2016)

En el enunciado, las personas que participan del culto se denominan como "peregrinos" para diferenciar relacionalmente del apelativo "salteños". Se induce de esta diferenciación al menos dos cuestiones: los "peregrinos" no son "salteños", están inscriptos en una territorialidad externa a la ciudad. Por otra parte, los "salteños" no son peregrinos del Cerro, hay una distinción entre uno y otro apelativo, además de que son menos que aquellos que vienen en micros. Los lugareños "concurren", pero no son "parte de", no hay -necesariamenteuna pertenencia a la creencia en la Virgen, marcando una frontera simbólica entre los cuerpos discursivos. El campo semántico termina de ubicar a los "peregrinos" como "otro" que viene de afuera sin mencionar que son "turistas", pero indicando su lugar de procedencia como es la provincia de Río Negro. La obliteración en el fragmento de nombrarlos como "turistas" y ubicarlos en una dimensión religiosa al categorizarlos como "peregrinos" es estratégica, por cuanto implica un corrimiento de la representación del culto del Cerro como parte del turismo religioso. Esto se encuentra vinculado, en cierta medida, a los esfuerzos del Arzobispado local en insertarse dentro de ésta lógica turística y disputar la centralidad de la organización de María Livia en este ámbito: en el año 2016 hubo un claro indicio de incorporarse dentro del turismo religioso al 
recibir a la Comisión Argentina del Turismo de la Fe promocionando, principalmente, los lugares legitimados por el dogma. Si bien la reunión incluía pensar a la Virgen del Cerro como parte del circuito religioso, había una preponderancia de espacios reconocidos por el Arzobispado, lo que implica, de algún modo, el cambio de postura de la institución local respecto al turismo ${ }^{13}$ y el accionar estratégico (De Certeau, 1996) en posicionar los símbolos y santuarios institucionalizados dentro de esta dinámica de consumo.

El corrimiento representacional de "turistas" a "peregrinos" que se ha intentado mapear está vinculado a las formas en que se construyen fronteras identitarias en los cuerpos que participan de la devoción y que son estratégica, contextual, relacional y situacionalmente identificados de maneras diferenciales y en concordancia -en cierto punto- con intereses de la Iglesia y el municipio. Así, en los fragmentos analizados se daba cuenta de cómo las personas que asistían al Cerro eran representadas como "turistas", reconociendo su actuación económi$\mathrm{ca}$, pero no necesariamente religiosa. Luego, se puede observar la manera en la que los medios representan a ese "turista" como un "peregrino", pues no solo forma parte del ritual de la vidente, sino, principalmente, de un culto colonial e institucionalizado como el Milagro. Esas negociaciones de sentido, sin embargo, nunca reconocen al "peregrino" de la Virgen del Cerro como un "salteño", porque siempre se terminan realizando distinciones entre ambos cuerpos. En cambio, las personas que concurren a la devoción del Milagro son "peregrinos" del interior de la provincia ("salteños") y "todos" los "peregrinos" que asisten a visitar a la vidente, implícitamente "turistas". Allí no solo se observa cómo un culto surgido en la colonia goza de la legitimidad de inscribir los cuerpos devotos dentro de una territorialidad interna asociada a la "salteñidad", sino cómo los medios visibilizan esas imágenes de mundo que están en concordancia con los postulados de la Iglesia, la cual erige la devoción del Milagro como intrínseca a la identidad local (Nava Le Favi, 2015).

El último párrafo muestra, finalmente, lo que quedaba latente en los otros enunciados: los cuerpos peregrinos que participan los sábados en el cerro no son "salteños", a pesar de que "algunos" de ellos concurren al lugar. Si bien la poca participación de los lugareños tiene concordancia con cifras reales que han dado cuenta investigaciones citadas en este trabajo, la distinción representacional pasa, también, por una diferencia de pertenencia religiosa, de cómo esos cuerpos van legitimando y demarcando las devociones: la presencia de los "salteños" en el cerro no implica que sean "peregrinos" de la Virgen ${ }^{14}$, esa identificación pareciera reservada solo a los outsiders, a los "turistas".

13 La noticia sobre la llegada de la Comisión Argentina del Turismo de la fe recibió la cobertura del diario El Tribuno de Salta, donde se mencionaron todos los lugares religiosos que ofrecía la provincia y la colaboración de la Iglesia local y el estado municipal en la reunión con la comitiva. Fuente: http://www.eltribuno.info/ buscan-impulsar-propuestas-turismo-religioso-salta-n719938

14 Hay un trabajo que muestra cómo la categoría de "peregrinos" está muy sedimentada para las personas que participan del culto del Milagro, constituyéndose en una representación sedimentada asociada a esta devoción (Nava Le Favi, 2016) 


\section{II}

\section{La capital de la fe": algunas apreciaciones finales}

En la primera parte del trabajo se ha intentado dar cuenta la manera en la que el culto a la Virgen del Cerro se inserta en el espacio local, cómo la organización mariana tiene estrategias sólidas de instalación y consolidación del culto y la manera en la que se encuentra una sobreimpresión de significados entre la devoción y una imagen de "argentinidad". Al abordar el contexto de surgimiento y visibilización del culto, se podía observar el modelo económico neoliberalista que atravesaba tanto el país como la provincia y la manera en la que esta última intentaba insertarse en las demandas de la globalización a través del turismo. Allí se estableció una aproximación a futuras líneas de investigación sobre las coincidencias entre el proyecto del gobernador Romero y la aparición mariana: la misma era capaz de conjugar un pasado colonial y tradicionalista (rasgos identitarios locales) para entrar en la lógica de la sociedad de consumo. Paralelamente, se fueron abordando las tensiones existentes con la Iglesia local y su grado de reconocimiento a nivel nacional como una advocación mariana.

En la segunda parte del trabajo, se fue pensando la manera en la que los medios construyen identificaciones sobre el cuerpo que participa del culto. En ese punto, se analizó un proceso de corrimiento representacional donde las personas que suben al cerro eran nominadas como "turistas" $\mathrm{y}$, al tiempo, "peregrinos", una categoría que usa la organización mariana para denominar a los miles de fieles que asisten cada sábado a ver a María Livia. Ese corrimiento puede arrojar diversas respuestas: por un lado, que la categoría de la práctica de la advocación comienza a ser legitimada en la esfera mediática local. Paralelamente, se puede suponer cómo la Iglesia ha cambiado su posición respecto al turismo religioso al punto tal que el Milagro, culto legitimado por el dogma, también se comienza a insertar dentro de la lógica del consumo turístico. Cabe destacar que la prensa local es una fuerte correa de trasmisión de una mirada conservadora y tradicionalista en concordancia con los valores que postula la Iglesia (Nava Le Favi, 2013), por lo cual el corrimiento representacional debe leerse -al menos- en esa clave de sentido: las identificaciones implican una negociación que pretende categorizar los cuerpos en su dimensión religiosa (y no solo económica), porque la disputa representacional (de la institución católica e incluso del municipio) también se está dando en el ámbito del turismo y en la centralidad que había adquirido el culto del cerro en este ámbito. Se podría decir que la estrategia discursiva es de igualación entre dos devociones para demarcar que la disputa es religiosa y turística.

Sin embargo, en los fragmentos analizados se mantiene una distinción: el turista/ otro puede ser un peregrino del culto del cerro (y también del Milagro), pero el "salteño" no. Así, los que vienen del interior de la provincia son participantes del culto colonial, porque su presencia legitima la devoción como el ícono de la salteñidad (Nava Le Favi, 2013). Sin embargo, ese cuerpo marcado por una territorialidad interna no comparte la identificación religiosa de ser "peregrino del cerro", esa representación identitaria pareciera reservada solo a la festividad reconocida por la institución. 
La batería de conceptos utilizados permite explorar la puja representacional en el campo discursivo-periodístico local que pasa -en algún punto- por quién tiene el monopolio religioso y económico, lo cual se traduce en luchas por la visibilidad y la legitimidad identitaria- territorial, un proceso que pasa por la categorización de los cuerpos. De esta manera, los conceptos permitieron una lectura articulada sobre los pliegues de sentidos en los que se van construyendo disputas y negociaciones dentro de un fenómeno complejo y posibilitan atender los procesos de comunicabilidad del mundo: quiénes, cómo y desde qué lugares de enunciación se enuncian (y se omiten) formas de representar los cuerpos, las identidades y los espacios que se habitan dentro de un culto mariano en tensión con las tramas de las culturas regionales.

La indagación intentó mapear una devoción que se inserta en "la capital de la $\mathrm{fe}^{\prime \prime}$ : nominación común en la prensa local para designar un espacio con una fuerte impronta de prácticas religiosas que, en lo no dicho, subsume la imagen de una sociedad tradicionalista y conservadora con una marcada legitimación de los valores del dogma católico. La aparición del cerro y las declaraciones de María Livia como la única intercesora de los mensajes de la Virgen no escapan a estas configuraciones culturales y político-religiosas que se inscriben en las tensiones y negociaciones de sentido rastreadas a lo largo de la reflexión. El abordaje de las identificaciones, las territorialidades, las representaciones y las fronteras permitieron pensar una pregunta por el poder de nominar los cuerpos, la cultura y el rol de los medios de comunicación en una aparición mariana que suma miles de adeptos en el país y el mundo, donde muchos de ellos afirman sentir, en la cima del cerro, "la presencia de la Virgen". ${ }^{15}$

\section{Referencias}

Álvarez Leguizamón, S. (2010). Introducción. En S. Álvarez Leguizamón (Comp.), Poder y Salteñidad. Saberes, políticas y representaciones sociales (1 Ed.) Salta: CEPHIA, Facultad de Humanidades.

Álvarez Leguizamón, S., y Villagrán, A. (2010). Artes de gobierno y estrategias de legitimidad en la etapa neoliberal en Salta, el gobierno de Juan Carlos Romero. En S. Álvarez Leguizamón (Comp.), Poder y Salteñidad. Saberes, politicas y representaciones sociales ( $1^{\mathrm{a}}$ Ed.) Salta: CEPHIA, Facultad de Humanidades.

Ambrosio, V., y Pereira, M. (2007). Case study 2: Christian/Catholic pilgrimage - studies and analices. En R. Raj, y N. D. Morphet (Eds.), Religious tourism and pilgrimage festivals management. Wallingford: CABI.

15 La frase forma parte de la práctica del culto. Los peregrinos suelen afirmar que sienten la presencia de la Virgen porque, por ejemplo, perciben perfume a rosas en el cerro. 
Ameigeiras, A. (2012). Ortodoxia doctrinaria y viejas ritualidades. Significados e implicancias en el catolicismo argentino de una aparición mariana. En Ameigeiras (Coord.), Cruces intersecciones, conflictos. Relaciones político reli-

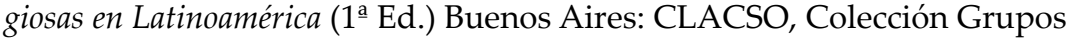
de Trabajo.

Ameigeiras, A., y Suárez, A. (2009). Peregrinación, devoción mariana y sanación: el caso de las apariciones de la Virgen en Salta. En XV Jornadas sobre Alternativas religiosas en América Latina, Santiago de Chile.

Ameigeiras, A., y Suárez, A. (2011). Las apariciones de la Virgen. El fenómeno de las apariciones de la Virgen en Salta: peregrinación, sanación y la misión de unir Oriente con Occidente. En Ciencias Sociales y Religión. Buenos Aires: UNSAM.

Ameigeiras, A., y Suarez, A. (2013). Buscando paz: Peregrinos al Cerro de las Apariciones de la Virgen en Salta. Sociedad y religión, 23(39), 117-150. Recuperado de http://www.scielo.org.ar/scielo. php?script=sci_arttext\&pid=S1853-70812013000100006\&lng=es\&tlng=es.

Angenot, M. (1998). Hegemonía, disidencia y contradiscurso. Reflexiones sobre la periferia del Discurso Social en 1889. En Interdiscursividades. De hegemonías $y$ disidencias (1 ${ }^{\underline{a}}$ Ed.) Córdoba: U.N.C.

Anderson, B. (1991). Comunidades imaginadas. México: Fondo de Cultura Económica.

Arancibia, V. (2009). Nacionalidad, territorios y memorias. Actas de las XII Jornadas Interescuelas de Historia, UNT, Tucumán [edición en CD].

Baumann, Z. (1999). La globalización: consecuencias humanas (1aㅡ. Ed.). Buenos Aires: Fondo de Cultura Económica.

Brubaker, R., y Cooper, F. (2002).Más allá de identidad. Apuntes de investigación del CECYP (7), 30-67.

Butler, J. (2002). Cuerpos que importan. Sobre los límites materiales y discursivos del sexo (1ํㅡㄹ Ed.) Buenos Aires: Paidós.

Butler, J. (2011). Violencia de estado, guerra y resistencia (1º Ed.). Buenos AiresBarcelona: Katz \& CCB.

Bourdieu, P. (2007). El sentido práctico (1 Ed.). Buenos Aires: Siglo XXI.

Campos, E. (2009). ¿Qué 20 años no es nada? Globalización, Posmodernidad y Rebelión en Argentina de Menem a Kirchner (1988-2008). Argumentos, 22(61), 95-123. 
Cebrelli, A., y Arancibia, V. (2005). Representaciones sociales. Modos de mirar y de hacer (1 ${ }^{\mathrm{a}}$ Ed.) Salta: CEPIHA-CIUNSa.

Cebrelli, A., y Arancibia, V. (2011). Las representaciones y sus márgenes. (In) visibilidades, imágenes y narrativas en situación de frontera cultural. Reflexiones Marginales. Revista de saberes de frontera (11), 7-13.

Cebrelli, A., y Arancibia, V. (2012). Luchas y transformaciones sociales en Salta (1 ${ }^{a}$ Ed.) Salta: Agencia de Ciencia y Técnica y CEPIHA.

Chaile, T. (2010). Los cultos religiosos en Salta. Procesos de Identidad y relaciones de Poder [Tesis de Doctorado]. Universidad Nacional de La Plata, La Plata.

Charaudeau, P. (2003). El discurso de la información. La construcción del espejo social. Barcelona: Gedisa.

De Certeau, M. (1996). La invención de lo cotidiano. I. El arte de hacer (2 Ed.). México: Universidad Iberoamericana.

Der Walde Moheno, L. (1997). Introducción a la cultura medieval. Manuales de Medievalia (Vol. 3) México: Universidad Autónoma de México.

Dri, R. (Coord.) (2007). Símbolos y fetiches religiosos en la construcción de la identidad popular ( $1^{\circ}$ Ed.). Buenos Aires: Editorial Biblios, Buenos Aires editores.

Eco, H. (2000). Tratado sobre semiótica general (5ํㅡㄹ.). Barcelona: Ed. Lumen.

Elías, N. (1996). La civilización de los padres y otros ensayos. Santa Fe de Bogotá: Editorial Norma.

Flores Klarik, M. (2010). De la representación del salteño y sus tradiciones a la construcción de los primeros discursos del turismo (1910-1945). En S. Álvarez Leguizamón (Comp.), Poder y Salteñidad. Saberes, políticas y representaciones sociales. Salta: CEPHIA, Facultad de Humanidades.

Fogelman, P. (2005). Coordenadas marianas: tiempos y espacios de devoción a la virgen a través de las cofradías porteñas coloniales. Trabajos y Comunicaciones (30), 55-67.

Fogelman, P., Ceva, M., y Touris, C. (Eds.) (2013). El culto mariano en Luján y San Nicolás. Religiosidad e Historia regional ( $1^{\circ}$ Ed.). Buenos Aires: Ed. Biblios.

Ford, A. (1985). Cultura dominante y cultura popular. En A. Ford, J. Rivera, y E. Romano, Medios de comunicación y cultura popular $\left(1^{\circ} \mathrm{Ed}\right.$.). Buenos Aires: Legasa.

Foucault, M. (2004). Securité, territoire, population. Cours au Collège de France, 1977-1978. París: Éditions du Seuil. 
González Viaña, M. (2013). Turismo religioso en Argentina. Un modelo para su desarrollo. $\left(1^{\circ} \mathrm{Ed}\right)$ Buenos Aires: Editorial La Colmena

Grimson, A. (2011). Los límites de la cultura (1 Ed.). Buenos Aires: Siglo XXI.

Hall, S. (1984). Notas sobre la deconstrucción de lo popular. En R. Samuels (Ed.), Historia popular y teoría socialista. Barcelona: Crítica.

Hall, S., y Dugay, P. (Comps.) (2003). Cuestiones de identidad (1a. Ed.). Buenos Aires: Amorrortu.

Laclau, E., y Mouffe, Ch. (2004). Hegemonía y estrategia socialista. Hacia una radicalización de la democracia. Buenos Aires: Fondo de Cultura Económica.

Maluf, S., Magalhaes, N., y Caggiano, S. (2008). As midias em múltiplas perspectivas. Ilha, 2(10), 8-16.

Martín-Barbero, J. (2003). De los medios a las mediaciones. Comunicación, cultura y hegemonía. Bogotá: Convenio Andrés Bello.

Millán Vázquez de la Torre, M., Morales Fernández, E., y Pérez Naranjo, L. (2010). Turismo religioso: estudio del camino de Santiago. Gestión Turística (13), 9-37. Recuperado de http://www.redalyc.org/html/2233/223314810001/

Nava Le Favi, D. (2013). La construcción del imaginario salteño respecto al culto de la Virgen del Milagro y la Virgen del Cerro en Salta. Identidades, actores sociales, conexiones y aristas de dos hechos religiosos locales. [Tesis de Licenciatura en Ciencias de la Comunicación]. Universidad Nacional de Salta, Facultad de Humanidades, Salta.

Nava Le Favi, D. (2014). "Yo siento el perfume de la Virgen": representaciones sociales en torno al culto de la Virgen del Cerro en la ciudad de Salta. Memorias XII ENACOM 2014 “El rol de la comunicación en el proceso de integración latinoamericana", Mendoza-Argentina.

Nava Le Favi, D. (2015). "Hoy convoca la fe": representaciones sociales e identidades en el caso del culto del Milagro en salta. Cuadernos de la Facultad de Humanidades y Ciencias Sociales - Universidad Nacional de Jujuy (48) 51-64.

Nava Le Favi, D. (2016). Territorialidades y espacio público. El caso de los devotos al culto del Milagro y Urkupiña en la ciudad de Salta. Memorias de las VI Jornadas del Norte Argentino de Estudios Literarios y Lingüísticos. San Salvador de Jujuy, Argentina.

Reguillo, R. (2008). Políticas de la (In)visibilidad. La construcción social de la diferencia. Clase № 5 del Curso Educación, Imágenes y Medios, Buenos Aires, FLACSO. 
Rodríguez, M.G. (2011). Palimpsestos: mapas, territorios y representaciones mediáticas. Reflexiones Marginales (16): El cine, sus meandros y sus ríos.

Rodríguez, M. G. (2014). Sociedad, cultura y poder ( $1^{\circ}$ Ed.). Buenos Aires: Universidad Nacional de San Martín.

Suárez, A., y Marchetta, A. (2015). La Virgen que se "aparece" en Salta: ¿por qué los lugareños le dan la espalda? Andes, 26(1). Recuperado de http://www. scielo.org.ar/scielo.php?script=sci_arttext\&pid=S1668-80902015000100009

Segato, R. (2008). La faccionalización de la república y el paisaje religioso como índice de una nueva territorialidad. En A. Alonso (Comp.), América Latina y el Caribe. Territorios religiosos y desafíos para el diálogo. Buenos Aires: CLACSO.

Turner, V. (1980). La selva de los símbolos (1 Ed.). Madrid: Siglo XXI

Varela, G. (2010). Enunciación televisiva y cuerpos de la seducción. Ponencia para el VIII Congreso Nacional y III Internacional de la Asociación Argentina de Semiótica Cartografía de investigaciones semióticas, Posadas, Misiones.

Verón, E. (1987). La semiosis social (1 Ed.). Barcelona: Gedisa. 